Articles

\title{
Economic Evaluation of Petroleum Projects
}

\section{(Basic Aspects)}

\author{
Dr. Hisham Yas \\ Economic \& Finance Dept.
}

\section{Abstract:}

Economic Evaluation is an essential step for assessing and studying and selecting new Petroleum Projects which involve different activities. This article presents basic aspects related to the Economic Evaluation Process such as concepts and requirements as well as the nature of Petroleum Projects. Particular focus was given to the new roles and skills and tools that are needed to achieve reasonable study of any Petroleum Project proposal.

الخلاصة

يعد موضوع التقبيم الاقتصادي خطوة اساسية في در اسة واختيار

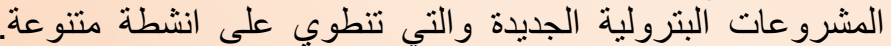

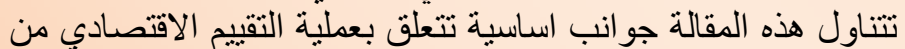

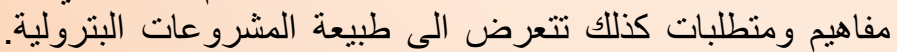

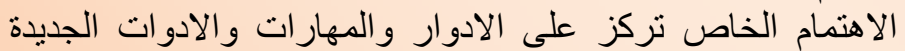

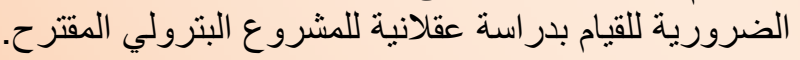
Introduction

Economic evaluation is an essential part of the process of studying available investment opportunities and supporting decision-making, by using special methodology and scientific analysis to select best options. Currently, many relevant areas have been developed such as technology, increasing number of economic and non-economic factors and new forms of fiscal terms, all of them make the modern economic evaluation more important and more complex.

Petroleum projects as investment opportunities require huge funds and with a long time to construct and they are associated with a series of risks and uncertainties. Therefore, the economic evaluation can be a main tool and reasonable way to find out best petroleum investment opportunities in terms of cost, revenue and risks. For those conditions, many methods and techniques have been developed to support the process of economic evaluation of petroleum projects. That became possible thanks to advanced programs, additional skillsand experiences as well as the outputs of mathematical and statistical sciences. These developments make some associated works easier and may help to increase the available information, decrease cost and risks, and ensure high speed and more accuracy.

\section{1- Economic Evaluation}

\section{1-1: Definition:}

Economic evaluation, as a tool or process, is used by many parties: companies, banks, investors, promoters, individuals and government agencies to consider a new project as an investment opportunity by studying its cost and revenues to find out and select the best options. This process involves using different data and information (monetary, quantitive and qualitative factors) to build projections, expressed in monetary terms, about initial investment, operating costs, finance sources, expected revenues and net cash flows, to calculate the net benefits or profitability indicators as well as taking into account the monetary time value, risk factor and changing conditions and assumptions, to make an initial judgment on project proposal. 


\section{1-2: Practical Requirements}

In practice, there are different requirements for the economic evaluation process. First, a special team should be formed to undertake divers evaluation works. This team mainly consists specialists

(Engineers, Economist, Accountant, Legal expert and Coordinator), each having sufficient experience in the area of the project. Second, providing technical background expressed as technical data and information of the project which is an essential source for computing the capital expenditures and operating costs and production. Third, legal frameworks and regulations (that should be up to date) involving taxes, duties and any other financial obligations that project will be subjected to. Fourth, collection of economic information about supply and demand, market prices, inflation rate, interest rate...etc. Fifth, the use of software programs has been designed for the economic evaluation purposes. All of those requirements should be combined and integrated throughout economic evaluation process.

\section{1-3: Factors and Indicators}

Economic evaluation may be a broad framework which includes many elements and tools, depending on the purpose of evaluation. This framework contains various issues (e.g. factors, concepts, indicators and equations) integrated with each other in the process of collecting data and information as well as computing results. More details are as follows:

\section{1-3-1: Economic Factors}

Information should be available from various sources about prices, inflation rate, interest rate, discount rate, exchange rate, taxes and depreciation. These will be used by the economist to build and analyzes the main elements of evaluation (cost and revenue as cash flows of project).

\section{1-3-2: The indicators of} Evaluation

Different criterias are used as evaluation indicators to examine and assess the project (investment opportunity). Although the return on investment is basically the most important indicator, economic evaluation is not limited to one indicator. In practice, there are some indicators, at least in this regard, that are applied to check and judge the feasibility of a given project. Economists may use two or more indicators, depending on the nature of the 
project and the intentions of the parties involved.

Evaluation's indicators, which are often calculated according to the particular formulas and equations in simple and complex ways, classified into two categories; the first category should consider the time value of money (discounted methods) such as Net Present Value (NPV), Internal Rate of Return (IRR), Discounted Payback and Profitability Index. The second should not (non discounted methods) such as Break-even Analysis, Exposure Point, Sensitivity Analysis and Cost/Benefit Ratio. The evaluation process may be expanded to use more indicators about financial and accounting issues (e.g. financial ratios) if the analysis of the financial statements related to the project is required.

\section{1-4: Risk Analysis}

Basically, the cash flows of the project, whether cash in or cash out, will occur in the future and their values will change according to the economic and technical circumstances. The work of evaluation team is to find out a certain economic value (best option). So it should therefore use its experience of the current and expected events to build up more realistic and acceptable assumptions. In this context, some special techniques are used such as (Probability Theory, Monte Carlo Simulation, Decision Tree and Sensitivity Analyses).

\section{1-5: Software Programs}

Many types of software programs are produced and developed to support and serve the work of economic evaluations. The purpose of these programs is to organize and analyze the related data and information (as inputs) and their results (as outputs) in flexible and quick ways. The software programs have been developed by using modern computer programs and advanced statistical and mathematical analysis. Key components of these programs include three main elements: inputs, processing and outputs. But the final design basically depends on the nature of the project and the details required from the parties involved.

Concerning the economic evaluation, program design needs various skills and experiences about (type and nature of the project, computer, evaluation process requirements as well as mathematical \& statistical tools). Currently, there is a large number of software programs, simple and complex; 
some depend on Excel, but others apply additional programs including new developed parameters and equations.

\section{1-6: Tasks of the Economist}

The economist is an essential member of evaluation team, and modern economic evaluations require different tasks from the economist. In other words, s/he may undertake many tasks throughout the evaluation process, depending on the type and volume of project as well as the required skills and experience in this area. As an economist, $s /$ he is supposed to have good knowledge and practices in economics, and s/he should have some knowledge on finance, mathematics, statistics, accounting, computer and contracting techniques as well as basic knowledge about the fundamentals of project proposal.

These necessary matters would enable the economist to perform various tasks efficiently ranging from the early steps up to the decision making. In this context, the economist could be involved in one or more tasks, including the following tasks: participating in the preparation of data and information, making analyses, building models, determining assumptions, organizing and calculating expected cash flows and profitability indicators, analyzing and explaining results, determining expected economic and financial risk, selecting the best options and providing suitable advices for the conditions of best and worst solutions.

\section{2- Economics of Petroleum Projects}

\section{2-1: Petroleum Projects}

The petroleum Industry consists of different activities related to the exploitation of the oil and gas resources under and above the ground (Exploration, Development, Production, Refining, Gas Processing, as well as Transportation and Distribution). In spite of this each one has its own specific features but they are interrelated and integrated. A petroleum project as an investment opportunity may not differ considerably from projects in the other types of industries. Simply, it is an allocation of capital to be spent on certain production factors that are required to establish a (Project) with commercial or non commercial objectives. As an important integrated part, it is necessary to distinguish between the types of petroleum project evaluations; simple or complex, high cost or low cost, undertaken by one individual or by a team, for a company or an investor...., 
depending on their cost and purposes.

In this regard, it must be considered that the funds, which are spent during the initial investment of the petroleum project at the early period, will go to hundreds of directions and channels. For example, purchasing equipments and materials from various sources, employing many people with different specialties, contracting with various companies to undertake some designs or conduct certain works and services...etc. Expected revenues that shall be received after relatively long time, under uncertain conditions, will only be from selling one or few products. This is why the economist should have sufficient knowledge and experience, and must be careful throughout the stages of economic evaluation process.

\section{2-2: Characteristics and Indicators}

Petroleum projects may differ considerably according to their various activities. Therefore, required details of project related to technical background and economics, which are made on the basis and characteristics of those activities, are also different. For example, the technical background of the exploration projects is substantially different from those of the refining projects, also between pipeline projects and gas plants. Ultimately, all of them should be expressed as monetary values and be classified as cost and revenue.

Concerning the software programs, there are many types of petroleum economics evaluation software programs, each one deals with a specific area such as; oil and gas reserves analysis, drilling works, exploration and production, refineries and gas plants. Any one who uses these programs must have multi-skills and good experience with the relevant projects or activities.

To take a look at main features of the cash flows for some of the petroleum projects, the following are some examples:

A. Within exploration and production projects, which often contain special contracting fiscal terms, the evaluation process is summarized in breaking down the cost into capital expenditures related to initial investment and operating cost related to requirements of production process such as transport and maintenance works. On the other hand the expected revenues will be achieved from selling oil and/or gas, to cover the costs and expected profits. 
B. Refining projects are relatively different, where the evaluation process includes: capital expenditure for constructing the refinery complex and operating costs for the maintenance works, material purchases and labor, but the most important in their cost is the feed crude oil purchases. Whereas revenues are generated from the yields of products sales

C. Pipeline projects include capital expenditures for establishing the pipeline, and operating cost for maintenance works and labor as well as taxes and duties. Revenues are made from the tariffs charged to those transporting crude oil or natural gas or products in the pipeline.

D. As for gas plants, huge funds should be spent (as capital expenditure) when establishing complex plants, with operating cost to purchase feed gas and some other required materials as well as the cost of maintenance works and labor. The revenues will be received from selling the plant's products (e.g. LPG and Dry Gas).

In addition, investment form is very important point, since petroleum investment is characterized by the use of special forms so called (International

Petroleum Contracts) for exploiting petroleum resources, which are classified in three main types: Concession, Production Sharing and Service Contracts. These contracts contain various terms such as (Bonus, Royalty, Petroleum Income Tax, Cost Oil and Profit Oil). Besides, there are special formulas computed by simple and complex equations such as (Sliding Scales, R-Factor, ROR-Factor, Price Cap and Netback). Those terms and formulas are essential items and have significant effects during the process of preparing, scheduling and computing cash flows and the expected final values of the project.

\section{Conclusion}

The evaluation of petroleum projects has general features which are similar to those in other industries. However, there are special and distinguished issues, essentially linked to the nature and conditions of petroleum projects, and they require special skills and experiences. In other words, there are many basic aspects surrounding the economic evaluation of petroleum projects that should be considered carefully and accurately, individually and collectively. 